\title{
How to Determine the Role of an Additive on the Length of Supramolecular Polymers?
}

\author{
Elisabeth Weyandt ${ }^{\diamond a, b}$ (i) \\ Mathijs F. J. Mabesoone ${ }^{\diamond a, b}(\mathbb{D})$ \\ Lafayette N. J. de Windt ${ }^{\diamond a, b}$ \\ E. W. Meijer ${ }^{a, b}$ (iD \\ Anja R. A. Palmans*a,b (D) \\ Ghislaine Vantomme*a,b (iD)

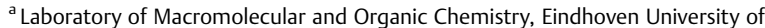 \\ Technology, P.O. Box 513, 5600 MB Eindhoven, The Netherlands \\ ${ }^{b}$ Institute for Complex Molecular Systems (ICMS), Eindhoven University of Technology, \\ P.O. Box 513, 5600 MB Eindhoven, The Netherlands \\ a.palmans@tue.nl \\ g.vantomme@tue.nl
}

${ }^{\diamond}$ These authors contributed equally.

Received: 31.01 .2020

Accepted after revision: 26.02.2020

DOI: 10.1055/s-0040-1708813; Art ID: om-20-0002pr

License terms: $(9)(1) \ominus(-)$

(c) 2019. The Author(s). This is an open access article published by Thieme under the terms of the Creative Commons Attribution-NonDerivative-NonCommercial-License, permitting copying and reproduction so long as the original work is given appropriate credit. Contents may not be used for commercial purposes, or adapted, remixed, transformed or built upon. (https://creativecommons.org/licenses/by-nc-nd/4.0/).

Abstract In polymer chemistry, modulation of sequence and control over chain length are routinely applied to alter and fine-tune the properties of covalent (co)polymers. For supramolecular polymers, the same principles underlying this control have not been fully elucidated up to this date. Particularly, rational control over molecular weight in dynamic supramolecular polymers is not trivial, especially when a cooperative mechanism is operative. We start this review by summarizing how molecular-weight control has been achieved in seminal examples in the field of supramolecular polymerizations. Following this, we propose to classify the avenues taken to control molecular weights in supramolecular polymerizations. We focus on dynamic cooperative supramolecular polymerization as this is the most challenging in terms of molecular weight control. We use a massbalance equilibrium model to predict how the nature of the interaction of an additive $\mathbf{B}$ with the monomers and supramolecular polymers of component $\mathbf{A}$ affects the degree of aggregation and the degree of polymerization. We put forward a classification system that distinguishes between B acting as a chain capper, a sequestrator, a comonomer, or an intercalator. We also highlight the experimental methods applied to probe supramolecular polymerization processes, the type of information they provide in relation to molecular weight and degree of aggregation, and how this can be used to classify the role of $\mathbf{B}$. The guidelines and classification delineated in this review to assess and control molecular weights in supramolecular polymers can serve to reevaluate exciting systems present in current literature and contribute to broaden the understanding of multicomponent systems.

Key words supramolecular polymers, chain-length control, chain capper

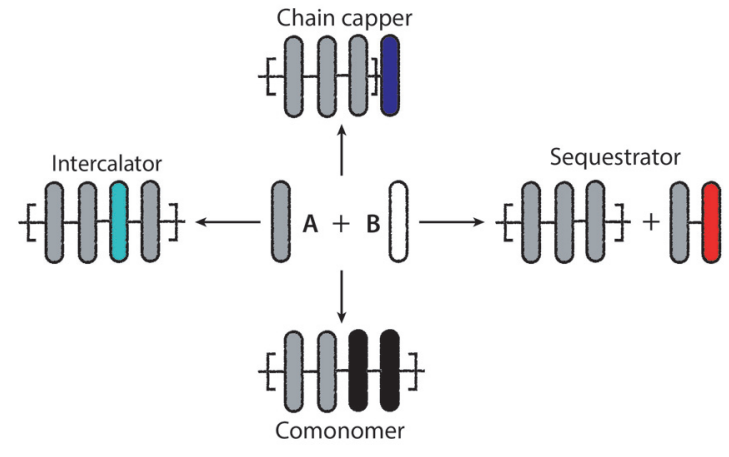

\section{Introduction}

This year, the polymer community celebrates the centenary of Staudinger's historic article published in Chemische Berichte in 1920 on the discovery of macromolecules. ${ }^{1}$ His invention was the starting point of polymer chemistry and can be regarded as one of the most successful disciplines in modern science with ample economic reward. In covalent polymerizations, a comprehensive understanding of the mechanisms of step-growth and chain-growth polymerizations has permitted to precisely control the monomer conversion, the degree of polymerization, and the nature of the end groups of (co)polymers by adding chain cappers or by regulating the initiator/monomer ratio. ${ }^{2}$ In supramolecular polymer chemistry, such high degree of control has been achieved in a number of exciting examples. ${ }^{3-5}$ However, a general and systematic approach based on mechanistic considerations to regulate degrees of polymerization, and thereby the molecular weights in dynamic systems, is still challenging. We recently delineated guidelines to classify supramolecular copolymers by analyzing them through the lens of the well-established field of covalent copolymerization with the aim to attain sequence control in supramolecular copolymerizations. ${ }^{6}$ Our goal in this review is to extend these guidelines and classify the effect of an additive $\mathbf{B}$ on the molecular weight of the supramolecular copolymers obtained.

Similar to covalent polymerizations, which occur through a step- or chain-growth mechanism, different mechanisms can be operational in a supramolecular polymerization. The mechanism of formation in supramolecular polymers can be classified as either isodesmic or cooperative growth and depends on the process through which each aggregate is formed. ${ }^{2}$ Isodesmic supramolecular polymerizations are the noncovalent analogue of step-growth polymerization, and are characterized by an association constant between the 
Biographical Sketch

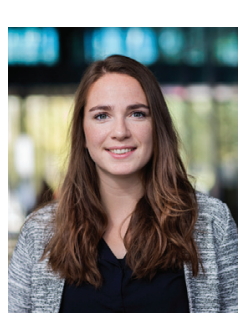

Elisabeth Weyandt received her MSc degree in chemistry (with honors) from RWTH Aachen University. During her studies, she worked with Prof. Andreas Walther on temporally pro- grammed, dissipative self-assembly in peptide hydrogels and with Prof. Timothy Swager at the Massachusetts Institute of Technology on responsive dynamic liquid colloids. In 2017 she joined the group of
Prof. E.W. Meijer as a PhD student, investigating responsive supramolecular assemblies and methods to control aggregate length in multicomponent supramolecular systems.

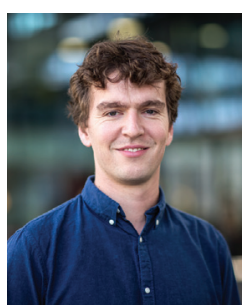

Mathijs F. J. Mabesoone obtained his MSc degree (cum laude) in chemistry in 2016 at the Radboud University. During his undergraduate degree, he worked with Prof. R.J.M. Nolte on host-guest

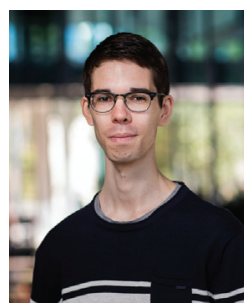

Lafayette N. J. de Windt received his MSc degree in Biomedical Engineering from Eindhoven University of Technology. During his master program, he joined the group of Prof. E.W. Meijer and Prof. Anja Palmans, where he investigated the folding of synthetic polymers in water. In

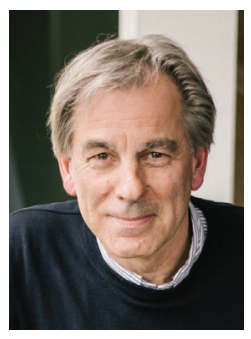

E.W. "Bert" Meijer is Distinguished University Professor and Professor of Organic Chemistry at the Institute for Complex Molecular Systems of the Eindhoven University of Technology. After receiving his PhD degree at the University of Groningen, he worked for 10 years in industry (Philips and DSM).

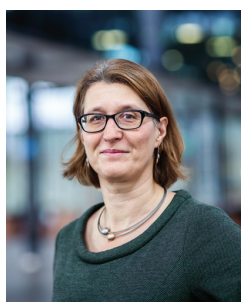

Anja R. A. Palmans obtained a degree in chemical engineering (1992) at the Eindhoven University of Technology (TU/e) and continued with a $\mathrm{PhD}$ on the topic of supramolecular chemistry (1997). After a postdoc at the ETH Zürich (Switzerland) and working at

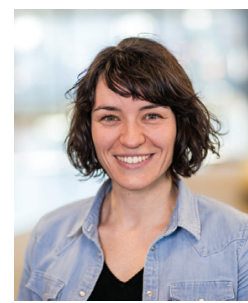

Ghislaine Vantomme studied chemistry at the Ecole Normale Supérieure (Cachan, France) from 2006 to 2010. After a stay in the laboratory of Prof. Koji Nakanishi and Prof. Nina Berova at Columbia University (New York), she received an MSc degree from the Pierre and Marie Curie University (Paris). In chemistry with porphyrin-based hosts and with Prof. C.J. Hawker at the University of California, Santa Barbara on coacervate hydrogels. Currently, he is completing his PhD in the group of Prof.
E.W. Meijer, where he focuses on experimental and computational analyses of competition and solvent interactions in supramolecular polymerizations. addition, he performed an internship in the group of Prof. Thomas Hermans at the Institute of Supramolecular Science and Engineering (University of Strasbourg), where he studied the self-assembly of perylene bisimide derivatives in aqueous solution. In 2017 he started as a PhD

In 1991 he was appointed in Eindhoven, while he had part-time positions in Nijmegen, Santa Barbara, and Mainz. He is a member of many editorial advisory boards, including the Journal of the American Chemical Society, and received a number of awards, including the Spinoza Award in 2001, the ACS Award for Polymer Chemistry in 2006,

DSM Research (The Netherlands), she became an assistant professor at TU/e in 2005 and an associate professor in 2010. Since 2019 she is a full professor in Supramolecular Chemistry and Catalysis at TU/e. Her research is aimed at the controlled folding of macromole- student in the group of Prof. E.W. Meijer and Prof. Anja Palmans. His research aims to gain understanding on supramolecular copolymerization by using a combination of theory and experiments.

the ACS Cope Scholar Award in 2012, the Prelog medal in 2014, the Nagoya Gold Medal in 2017, and the Chirality Medal in 2018. He is a member of a number of academies and societies, including the Royal Netherlands Academy of Science, where he was appointed as an academy professor in 2014.

cules with pendant recognition motifs into well-defined, compartmentalized particles. In addition, she is intrigued by the ability to control how small molecules interact and form defined, macromolecular structures that exhibit a function (electronic or biological).
2014 she defended a PhD under the supervision of Prof. Jean-Marie Lehn at the Institute of Supramolecular Science and Engineering (University of Strasbourg). Switching to materials chemistry, she joined Eindhoven University of Technology as a postdoctoral fellow to work with Prof. E.W. Meijer and Prof. Dirk Broer. In 2019 she was appointed an assistant professor at TU/e. Her research interests include the understanding of the fundamentals of supramolecular chemistry and their translation into adaptive materials. 
supramolecular units which is identical for each monomer addition to the growing polymer chain. Cooperative supramolecular polymerizations are correlated to chain-growth polymerizations. In this case, the polymerization starts with the formation of a nucleus which is generally an energetically unfavorable, small aggregate. Once formed, monomers add to the nucleus to form long polymers. The association constants involved in the nucleating step are lower than those involved in the growth of the polymer, reflecting the generally low stability of the nucleus and the favored formation of long polymers. The nature of the mechanism directly influences the molecular-weight distributions, average chain lengths, and sensitivity of the systems to concentration and temperature in a supramolecular polymerization. ${ }^{2}$ As a consequence, the effect of an additive in a supramolecular polymerization should also show different effects depending on the mechanism involved. Therefore, we distinguish between isodesmic or cooperative polymerization and thermodynamically or kinetically controlled elongation mechanisms when discussing the effect of an additive. We focus our discussion on thermodynamically controlled cooperative supramolecular polymerizations as control over chain length in these polymerizations is the most challenging. Due to the dipolar coupling in the bifunctional binding sites (e.g., hydrogenbonded amides), the reactivities of the polymer end and the monomer are different. Upon polymerization, binding at one site of the monomer is not necessarily equal to binding to the other site. This difference has to be taken into account when engineering additives to control the molecular distribution. This poses a considerable challenge to rationally design the desired chain length in cooperative supramolecular polymerizations. In contrast, when polymerizations are kinetically controlled, chain-length control is considerably more straightforward by, for instance, tuning the monomerto-initiator ratio. However, a general understanding of chain-length control in supramolecular polymers at thermodynamic equilibrium is still lacking.

We structure this review by first summarizing how molecular-weight control has been achieved in seminal examples in the field of supramolecular polymerizations, both under thermodynamic and kinetic control. Following this, we focus on dynamic cooperative supramolecular polymerizations. We use a mass-balance equilibrium model to predict how the nature of the interaction of an additive $\mathbf{B}$ with the monomers and supramolecular polymers of component $\mathbf{A}$ affects the degree of aggregation $\left(\phi_{\text {agg }}\right)$ and the degree of polymerization $\left(D P_{n}\right)$. Based on the Gibb's free energies of interaction $\Delta G_{\mathrm{AA}}, \Delta G_{\mathrm{BB}}$, and $\Delta G_{\mathrm{AB}}$ between the additive $\mathbf{B}$ and the supramolecular monomers and polymers of $\mathbf{A}$, we put forward a classification system. This system distinguishes the role of $\mathbf{B}$ acting as a chain capper, sequestrator, comonomer, or intercalator. We then highlight the experimental methods applied to probe the supramolecular polymerization processes, which type of informa- tion can be obtained in relation to molecular weight and dispersity, and how this can be used to classify the role of additive $\mathbf{B}$ in the copolymerization. Although monofunctional terminal monomers are often called chain stoppers in the literature, we here use the term chain cappers as this emphasizes thermodynamic rather than kinetic control over the chain length.

\section{Molecular-Weight Control in Supramolecular Polymerizations: State-of-the-Art}

\section{Chain-Length Control in Isodesmic Supramolecular Polymers under Thermodynamic Control}

The control over the chain length of supramolecular polymers has been of interest ever since the first reports on supramolecular polymerizations appeared. In supramolecular polymers derived from monomers that link two supramolecular binding motifs, such as ureidopyrimidinones (Figure 1), ${ }^{7}$ Hamilton wedges with cyanuric acid, ${ }^{8}$ cyclodextrin with viologens, ${ }^{9}$ and others. ${ }^{10-12}$ The length of the supramolecular polymers can be completely controlled by tuning the stoichiometry and association strength of a monofunctional competing chain capper. This well-established method to obtain chain-length control with bifunctional monomers under thermodynamic control has been recently reviewed elsewhere, so it will not be discussed in great detail here. ${ }^{5}$

The most straightforward way to control the chain length of supramolecular polymers is through controlling the association constant and the overall concentration of material in the system. ${ }^{13}$ In the case of an isodesmic supramolecular polymerization, the numberaverage degree of polymerization is given by the supramolecular analogue of the Carothers equation (Equation 1):

$$
D P_{\mathrm{n}}=\frac{1}{1-K \cdot[\mathrm{M}]}
$$

Equation 1 Number-averaged molecular weight for an isodesmic supramolecular polymer.

with $K$ the association constant for the addition of a monomer to the growing polymer and $[\mathrm{M}]$ the equilibrium concentration of free monomer. The weight-averaged molecular weight is given by Equation 2:

$$
D P_{\mathrm{w}}=\frac{1+K \cdot[\mathrm{M}]}{1-K \cdot[\mathrm{M}]}
$$

Equation 2 Weight-averaged molecular-weight $\mathrm{DP}_{\mathrm{w}}$ for an isodesmic supramolecular polymer.

and consequently, the dispersity of the polymerization is given by the ratio between the weight- and number-averaged 
molecular weights: $1+K[\mathrm{M}]$. Analogous to step-growth polymers, the dispersity of isodesmic polymers approaches 2 as the system becomes increasingly aggregated.

The mass-balance equation of isodesmic polymerizations can be solved analytically ${ }^{13}$ to obtain Equation 3 as an expression of the number-averaged degree of polymerization as a function of the overall monomer concentration, $[\mathrm{M}]_{\text {tot }}$ :

$$
D P_{\mathrm{n}}=\frac{1+2 \cdot K \cdot[\mathrm{M}]_{\mathrm{tot}}+\sqrt{4 \cdot K \cdot[\mathrm{M}]_{\mathrm{tot}}}}{\sqrt{4 \cdot K \cdot[\mathrm{M}]_{\mathrm{tot}}+1}+1}
$$

Equation 3 Number-averaged degree of polymerization $D P_{\mathrm{n}}$ as a function of $[\mathrm{M}]_{\text {tot }}$ for an isodesmic supramolecular polymer.

When the system is in a strongly aggregated regime, $K$ $[\mathrm{M}]_{\text {tot }} \gg 1$, and hence Equation 4 is obtained:

$$
D P_{\mathrm{n}} \approx \frac{2 \cdot K \cdot[\mathrm{M}]_{\mathrm{tot}}+\sqrt{4 \cdot K \cdot[\mathrm{M}]_{\mathrm{tot}}}}{\sqrt{4 \cdot K \cdot[\mathrm{M}]_{\mathrm{tot}}}} \approx \sqrt{K \cdot[\mathrm{M}]_{\mathrm{tot}}}
$$

Equation $4 D P_{n}$ approximation for an isodesmic supramolecular polymer in the strongly aggregated regime.

In contrast to polymers formed from bifunctional supramolecular monomers (Figure 1), chain-length control over cooperative supramolecular polymers has proved to be more challenging. Nonetheless, recent progress showed that such control is feasible, especially in kinetically controlled supramolecular polymerizations.

\section{Kinetic Chain-Length Control in Supramolecular Polymers}

In recent years, the synthesis of near-monodisperse supramolecular polymers through the seeded growth onto

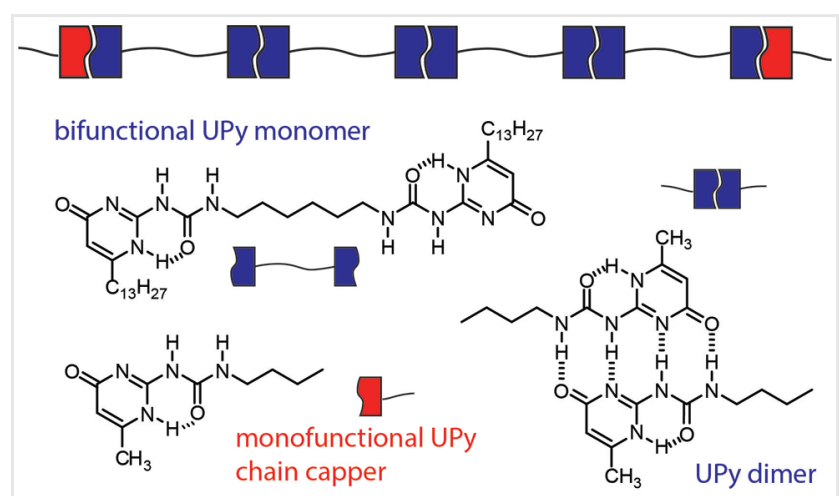

Figure 1 Schematic representation of chain-length control in ureidopyrimidone (UPy) supramolecular monomers. Chemical structures of the bifunctional UPy monomer and the monofunctional UPy chain capper.

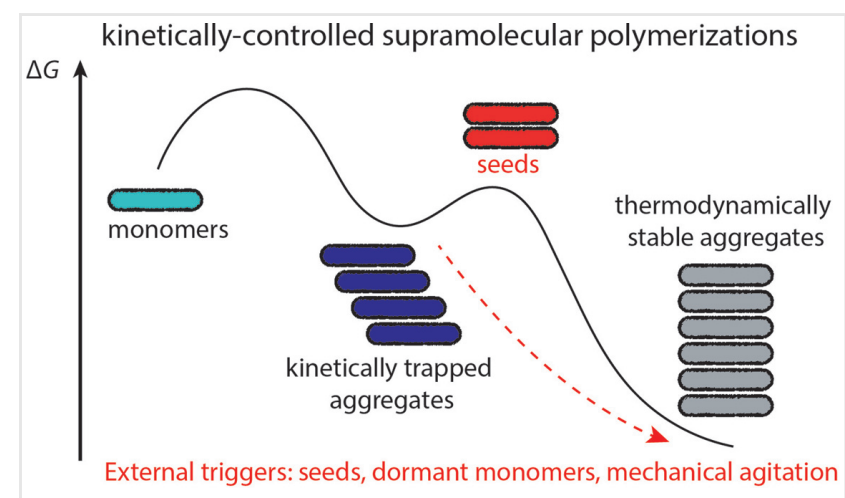

Figure 2 Schematic representation of the energy landscape of kinetically controlled supramolecular polymerizations. Pathway complexity leads to different types of aggregates, which can be interconverted by using seeds, dormant (responsive) monomers, or mechanical agitation such as sonication or stirring.

small nuclei has attracted a lot of attention (Figure 2). The first examples of such kinetically controlled polymerization have been described by the group of Manners and Winnik. ${ }^{14}$ In several reports, they showed the crystallization driven self-assembly (CDSA) of block copolymers of polyferrocenylsilane (PFS) and various other polymers into cylindrical micelles. Small crystallites serve as nuclei for the formation of self-assembled structures with very narrow molar mass dispersities. ${ }^{14-16}$ Using this approach, more complex architectures, such as diblock, ${ }^{17}$ triblock, ${ }^{18}$ sequential multiblock copolymers ${ }^{19}$ of controlled length, and even size-controlled sheets ${ }^{20}$ have been achieved. In addition to PFS-based polymers, supramolecular aggregates of controlled length through CDSA have also been reported for several other systems, all incorporating crystallizing moieties, such as polylactides or organometallic compounds. ${ }^{21-23}$

The use of mechanical agitation to obtain seeds for the synthesis of monodisperse supramolecular aggregates with controlled length has been shown in CDSA, ${ }^{24}$ but has most thoroughly been investigated in the supramolecular polymerization of dithiol-bridged macrocycles by the group of Otto. In a series of reports, ${ }^{25-27}$ Otto and coworkers showed that by controlling the stirring speed and shear rate in the solution, the equilibrium length of the supramolecular polymer can be controlled.

A third way to achieve control over supramolecular polymer length is the use of living supramolecular polymerizations. The group of Sugiyasu and Takeuchi reported the first living supramolecular polymerizations, ${ }^{28}$ in which a porphyrin monomer is trapped in off-pathway, kinetically trapped aggregates, which over time converted into thermodynamically stable supramolecular polymers (Figure 2). Seeds obtained by fragmenting the supramolecular polymer proved to accelerate the 
formation of the supramolecular polymer in samples containing kinetically trapped monomers. Moreover, by controlling the seed-to-monomer ratio, control over the polymer length has been achieved. The use of small seeds to synthesize supramolecular polymers of controlled length has since been shown in several other systems, such as zinc-chlorins, ${ }^{29}$ perylenes, ${ }^{30-35}$ pyrenes, ${ }^{36}$ naphthalenes, ${ }^{37}$ carbonyl-bridged triarylamine trisamides, ${ }^{38}$ and peptide amphiphiles. ${ }^{39}$ Recently, the groups of Che and Zhao expanded the use of seeded polymerization to generate also two-dimensional aggregates of controlled surface area. ${ }^{34,40}$

Another approach to realize living supramolecular polymerizations is the use of a dormant initiator or monomer. ${ }^{41}$ This approach was first realized by Aida and coworkers in a corannulene-based monomer, which does not assemble into hydrogen-bond stabilized supramolecular polymers due to the formation of intramolecular hydrogen bonds rather than intermolecular hydrogen bonds. ${ }^{42}$ Upon addition of a methylated monomer, which cannot form intramolecular hydrogen bonds, but acts as an acceptor for intermolecular hydrogen bonds, the intramolecular hydrogen bonding of the dormant monomer is broken and highly stable supramolecular polymers of controlled length are formed with narrow molar mass dispersities between 1.2 and 1.3. A similar approach was realized by the groups of Sugiyasu and Takeuchi in a photoswitchable azobenzene system, where controlled living supramolecular polymerization onto a preformed seed could be initiated by photoactivation of the dormant monomer. ${ }^{43}$ The groups of Ghosh ${ }^{37}$ and Sugiyasu ${ }^{44}$ later also showed that the solvent in which the seeds and polymers, respectively, are prepared can be used to liberate a dormant monomer to form living supramolecular polymers of controlled degrees of polymerization. In addition, Ghosh and coworkers also showed that differences in sample preparation can be employed to generate dormant monomers or seeds to initiate living supramolecular polymerizations. ${ }^{45}$ In a recent report, Sugiyasu and coworkers additionally revealed that complexation of the monomers with a "dummy" monomer can also be used to render the monomer dormant, after which a seeded living supramolecular polymerization could be initiated. $^{46}$

Kinetic trapping of the monomer has been a very effective strategy to obtain control over the chain length of supramolecular polymers in kinetically controlled polymerizations. ${ }^{47}$ A common structural motif in the molecular design of the monomers that shows living supramolecular polymerization is the presence of flexible linkers between the core and the hydrogen-bonding moieties that stabilize the polymer. The flexibility in the linkers enables the presence of various hydrogen-bond stabilized geometries, which are required to form both an off-pathway aggregate or a dormant monomer state and the supramolecular polymer. Interestingly, large $\pi$-surfaces, which promote aggregation and are often associated with kinetic traps, do not appear to be a general design requirement, as indicated by the photoswitchable system of Endo et al. ${ }^{43}$ Despite the successes of kinetic control to synthesize supramolecular polymers of controlled lengths, this approach comes with the inherent compromise of the long-term stability of these systems.

\section{Chain-Length Control of Out-of-Equilibrium Supramolecular Polymers}

Recently, inspired by the dynamicity of living systems, supramolecular polymers have been studied under nonequilibrium conditions. ${ }^{48-50}$ Amazing examples have shown that coupled processes can lead to continuous chain growth and shrinkage of supramolecular polymers. ${ }^{51,52}$ When a fine tuning between the kinetics of feedback mechanisms and the polymerization processes is achieved, complex dynamic patterns reminiscent of living systems can emerge. ${ }^{53}$ The recent examples of such systems have been reported elsewhere ${ }^{48,49,54}$ and are not further discussed in this review.

\section{Thermodynamic Chain-Length Control in Cooperative Supramolecular Polymers}

Another way to arrive at length control in supramolecular polymers can, in principle, be achieved under thermodynamic equilibrium. In isodesmic supramolecular polymers, this control is easily achieved through the addition of a monofunctional chain capper (see above). In contrast, in cooperative supramolecular polymerizations, when the binding sites on the monomers are electronically coupled, only few reports on chain length control have been published.

In these cases, a nucleation event precedes the thermodynamically favorable elongation of the polymer, which leads to the formation of supramolecular polymers with high degrees of polymerization. The degree of polymerization is strongly dependent on the relative stability of the nucleus compared to the elongated polymer. This relative stability is typically expressed in a cooperativity parameter, $\sigma$, which equals the ratio between the equilibrium constant for the addition of a monomer to aggregates smaller than the nucleus size and the equilibrium constant for the addition of a monomer to polymers larger than the nucleus. Zhao and Moore derived that for cooperative supramolecular polymerizations, the number-average degree of polymerization is given by Equation $5^{13}$ : 


$$
D P_{\mathrm{n}}=\frac{\sigma+(1-\sigma) \cdot(1-K \cdot[\mathrm{M}])^{2}}{\sigma \cdot(1-K \cdot[\mathrm{M}])+(1-\sigma) \cdot(1-K \cdot[M])^{2}}
$$

Equation 5 Number-average degree of polymerization $D P_{n}$ for a cooperative supramolecular polymer.

The weight-averaged molecular weight is given by Equation 6:

$$
D P_{\mathrm{w}}=\frac{\sigma \cdot(1+K \cdot[\mathrm{M}])+(1-\sigma) \cdot(1-K \cdot[M])^{3}}{\sigma \cdot(1-K \cdot[\mathrm{M}])+(1-\sigma) \cdot(1-K \cdot[M])^{3}}
$$

Equation 6 Weight-average degree of polymerization $D P_{\mathrm{w}}$ for a cooperative supramolecular polymer.

The free monomer concentration, [M], is strongly dependent on the elongation constant, $K$, and the cooperativity parameter, $\sigma$. As a result, the mass-balance equation cannot be solved analytically and no approximations for the degree of polymerization of nucleated polymerizations as a function of the total concentration of monomers in the system can be derived. However, numerical simulations using the model outlined by Zhao and Moore ${ }^{13}$ and later extended by the groups of Markvoort and ten Eikelder ${ }^{55,56}$ show that a square-root dependency on both association constant and total concentration can be observed, while an exponential increase of the degree of polymerization is observed when the nucleation penalty is varied. In Figure 3, we demonstrate the changes in degree of aggregation with increasing concentration (a) and for varying cooperativity parameter $\sigma$ going from an isodesmic to a cooperative system (b).

Experimentally, the chain length of supramolecular polymers can thus be modulated by either controlling the concentration or the association constant. Although these two parameters can easily be controlled, they are also very dependent on the external conditions. Evaporation of the solvent or changes in temperature directly affect the degree of polymerization. As a result, controlling temperature, solvent quality, ${ }^{57}$ or monomer concentration is not a robust method to modulate the chain length of supramolecular polymers.

Similar to the isodesmic polymers, the addition of chaincapping agents has been evaluated to control polymer length in thermodynamically controlled cooperative supramolecular polymerizations. The 2,4-bis(2-ethylhexylureido)toluene (EHUT) system developed by the group of Bouteiller has been extensively studied and was shown to polymerize in a cooperative manner. ${ }^{58}$ The first chain cappers identified for the EHUT system, which polymerizes through the formation of hydrogen bonds between urea moieties, consisted of $\mathrm{N}$ methylated derivatives of the monomer (Figure 4). ${ }^{59-61}$ As a result of the $\mathrm{N}$-methylation, the chain cappers act as acceptors for intermolecular hydrogen bonds, but not as donors. This monofunctionality results in a sharp decrease of the chain length upon addition of the chain capper to the system. ${ }^{62-64}$ In a)

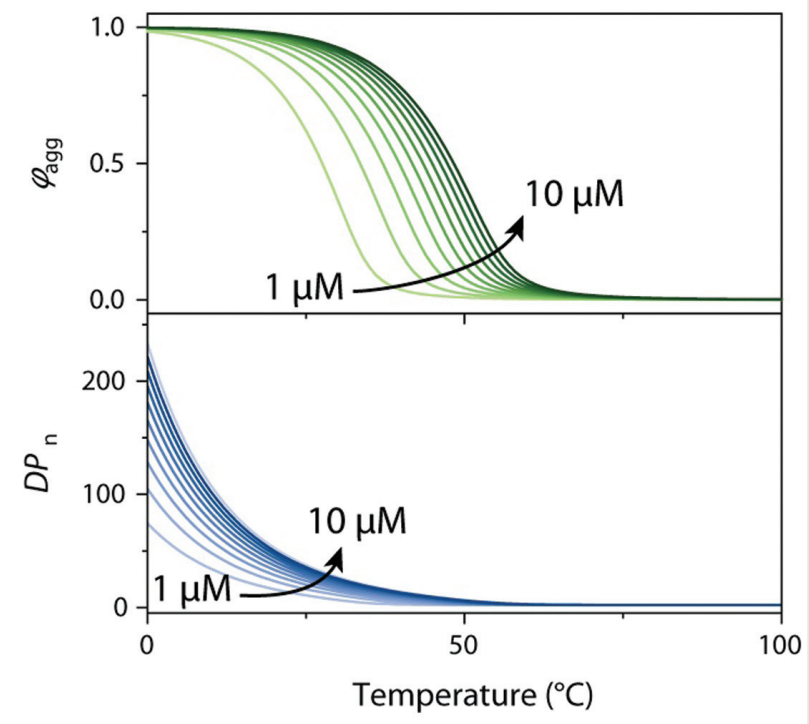

b)

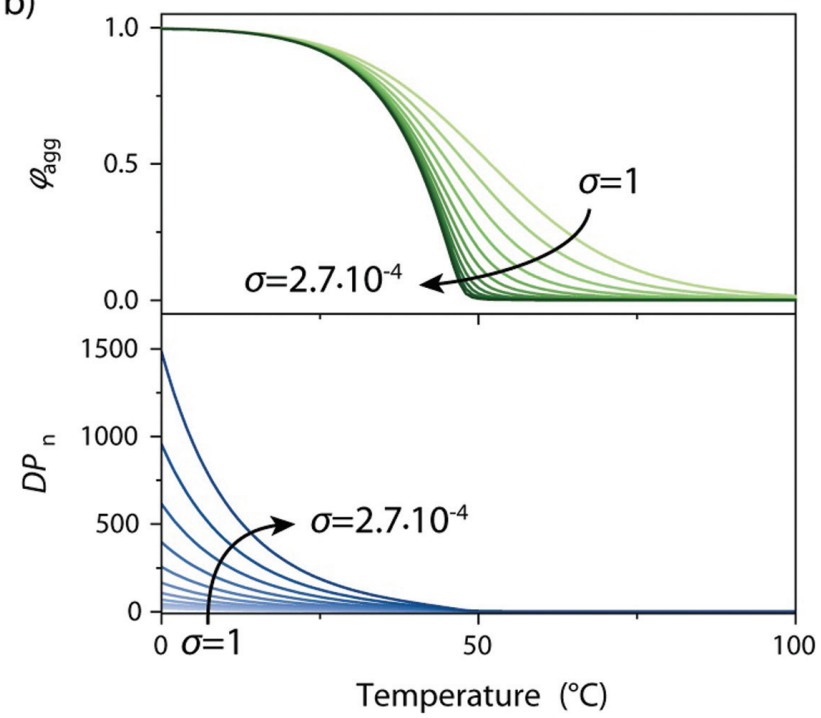

Figure 3 Changes in the degree of aggregation $\phi_{\text {agg }}$ (top panels) and $D P_{\mathrm{n}}$ (bottom panels) with a) increasing concentration at a nucleation penalty of $10 \mathrm{kJmol}^{-1}$ and b) changes in cooperativity factor $\sigma$ calculated at $5 \mu \mathrm{M}$ with a thermodynamic mass-balance model (parameters: enthalpy of elongation $\Delta H_{\mathrm{e}}=-90 \mathrm{kJmol}^{-1}$, entropy of elongation and nucleation: $\Delta S_{\mathrm{e}}=\Delta S_{\mathrm{n}}=-18 \mathrm{Jmol}^{-1} \mathrm{~K}^{-1}$ ).

addition to the development of EHUT-derived chain cappers, Bouteiller and coworkers also reported that anions function effectively to decrease the chain length of the supramolecular polymers of EHUT. ${ }^{65}$ Moreover, thioureas, being weaker hydrogen bond acceptors but strong donors, also act to reduce the chain length. ${ }^{59}$

A similar strategy based on the monofunctionality of the chain capper was reported by the group of Ghosh with photoswitchable amide-functionalized naphthalenediimides 
<smiles>CCCCC(CC)CNC(=O)Nc1ccc(C)c(NC(=O)NCC(CC)CCCC)c1</smiles><smiles>CCCCN(CCCC)C(=O)Nc1ccc(C)c(NC(=O)N(CCCC)CCCC)c1</smiles>

Figure 4 Schematic representation and molecular structures of EHUT/DBUT monomer and chain-capper system, which allows for control over the chain length at thermodynamic equilibrium.

(NDIs). ${ }^{66}$ In this system, the amides of the NDIs were protected with a photolabile 0 -nitrobenzyl group to obtain a chaincapping agent which accepts hydrogen bonds, but cannot act as a donor. The addition of up to $40 \mathrm{~mol} \%$ of the chain capper resulted in a considerable decrease in the viscosity of the samples. In addition, upon irradiation of the chain capper, the photolabile $\boldsymbol{o}$-nitrobenzyl group was removed, liberating the monomer and polymers of controlled length were obtained. Applying a similar approach to control the chain length of supramolecular polymers based on 1,3,5-benzenetricarboxamide (BTA) polymers failed. Although $N$-methylated BTA can decrease the viscosity of a concentrated solution of BTA fibers, it was shown that it is not a chain capper of BTA polymers in diluted solution. ${ }^{67}$ A different preorganization mode of the amides of the $N$-methylated BTA was proposed to explain the unfavorable interaction between this additive and the BTA stacks. Instead, sterically crowded BTA derived from a hemicryptophane cage ${ }^{68}$ could act as ideal chain cappers of BTA polymers but this remains to be proven.

Chain capping for water-based systems has also been presented. An elegant design to control the chain length of water-soluble supramolecular polymers was reported by the group of Hud. ${ }^{69}$ In this approach, water-soluble supramolecular polymers of discs of hydrogen-bonded triaminopyrimidine and cyanuric acid are shortened in the presence of positively charged additives such as pyridinium-functionalized porphyrins, ethidium bromide, and several other compounds. ${ }^{69}$

Furthermore, the control of supramolecular polymer length has also been achieved by external triggers, with the incorporation of photo- and redox-responsive additives. Recently, Hud and coworkers extended their work and exploited the redox-switching property of methylene blue to reversibly transform a hydrogel composed of long fibers into a solution of short aggregates. ${ }^{70}$ The approach relies on the interaction of the electron-poor additive with the electron-rich aromatic monomers of the supramolecular polymers and is particularly efficient because the additives cannot form supramolecular homopolymers. Moreover, photoresponsive additives have been explored to control the length of BTA supramolecular polymers. Our group developed an additive able to switch reversibly from an intercalator to a chain capper upon light irradiation. ${ }^{71}$ This additive has a similar core to the BTA monomer, but contains a photoswitchable acyl hydrazone group on one side arm. The chain shortening induced by light was explained by the steric hindrance generated at the chain ends upon photoisomerization of the acyl hydrazone from the $E$ to the $Z$ isomer.

Besides the few reports of chain cappers to control the length of cooperative supramolecular polymers, additives that interact with the free monomers have also been employed. This strategy is similar to the addition of small amounts of good solvents that stabilize the monomer and thus decrease the polymer chain length. ${ }^{57}$ An additive sequestrates the free monomer into stable short species, upon which the supramolecular polymer partly depolymerizes to restore its equilibrium with the free monomer. A typical example is the use of pyridines to depolymerize metalated porphyrin-based supramolecular polymers. $^{72}$ Our group reported that rationally designed competition between a zinc-metalated porphyrin polymer and a pyridine ligand can be employed to control the formation of supramolecular polymers by either dilution ${ }^{73}$ or switching of a photoresponsive pyridine. ${ }^{74}$ Another example used a similar strategy with ester-bonded dimers as additives, which sequester the monomers from polymerizing by the competitive formation of stable side species. ${ }^{75}$

And finally, Nakashima and coworkers showed that the polymer length can also be tailored by varying the ratio between enantiomers of a perylene bisimide-functionalized binaphthalenes. ${ }^{76}$ By controlling the enantiomeric excess of the monomers, the extent of homo- and heterointeractions could be balanced. Using a combination of scanning electron microscopy (SEM), transmission electron microscopy (TEM), atomic force microscopy (AFM), and cryo-TEM, they showed that upon increasing the enantiopurity of the system, the supramolecular polymers become longer.

\section{Challenges in the Design of Supramolecular Chain Cappers}

The molecular design rules for chain cappers to tune the length of isodesmic supramolecular polymers are well understood: a simple monofunctional chain capper with similar binding properties to the bifunctional monomer suffices to control the chain length. In contrast, in cooperative polymerization, the binding affinity of the chain capper with the polymer is inevitably different from the binding affinity of the monomer with the polymer. Additionally, interactions of the chain capper with the free monomer cannot be ruled out. 
As a result, a complex situation where many interactions operate simultaneously makes the molecular design of a chain capper for cooperative supramolecular polymers and the characterization of the whole system very challenging. In the literature, it is not always clear how this additive, often reported as a chain capper, controls the length of the polymer. Then, the question is how this additive interacts with the polymer, with the monomer, and whether it interacts by chain capping, by sequestration, by intercalation, or by copolymerization. It would certainly be insightful to go into the experimental details of these examples to confirm the role of the additive and whether it is a chain capper or any of the others. The next part of this review aims at identifying and generalizing principles and phenomena using mathematical modeling to elucidate the role of an additive in supramolecular polymerization.

\section{A Classification of Additives (B) for Controlling Chain Lengths in Thermodynamically Controlled Supramolecular Polymerizations}

We here illustrate that different effects of an additive on $D P_{\mathrm{n}}$ and $\phi_{\text {agg }}$ can result from different modes in which the additive interacts with supramolecular polymers. As the influence of an additive $\mathbf{B}$ on monomers $\mathbf{A}$ and the chain length of supramolecular polymers $\operatorname{poly}(\mathbf{A})$ can be very complex, we first define the different general roles $\mathbf{B}$ can take in the coassembly of $\mathbf{B}$ and $\mathbf{A}$. In the most general cases, $\mathbf{B}$ can interact with $\mathbf{A}$ either as a chain capper, sequestrator, intercalator, or comonomer (Scheme 1). This study is applicable to both isodesmic and cooperative supramolecular polymerizations, but we focus our examples on cooperative supramolecular polymerization.

We define chain capper as the case where monomer $\mathbf{B}$ exclusively attaches to either end of $\operatorname{poly}(\mathbf{A})$ chains. Monomer B acts as a sequestrator when it complexes with free monomer A, effectively reducing the concentration of $\mathbf{A}$ but not participating in the supramolecular polymerization. Monomer $\mathbf{B}$ is an intercalator when it intercalates between two $\mathbf{A}$ residues within chains of poly (A), but cannot intercalate next to another B. Finally, B can also act as a true comonomer, forming copolymers with $\mathbf{A}$ of

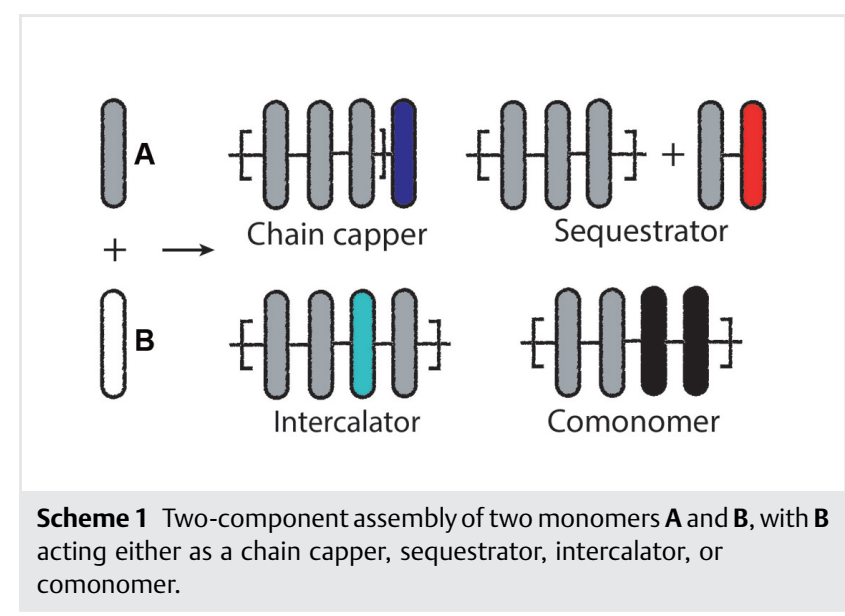

varying microstructures. In this case, monomer $\mathbf{B}$ can associate with both $\mathbf{A}$ and $\mathbf{B}$ monomers, depending on the respective equilibrium constants.

In theoretical models of supramolecular homopolymerization, the growth of polymer chains is generally described by the addition of monomers at the ends of a growing polymer chain. ${ }^{13,56,77,78}$ Accordingly, the growth of a polymer chain in two-component copolymerizations can -in its most simple form-be described with four equilibrium constants. ${ }^{79}$ We here propose to classify the above outlined roles of the additives according to the equilibrium constants describing two-component copolymerizations (Table 1). By considering an additive as a component, models of two-component copolymerizations can be implemented not only to classify additives but also to simulate the different modes in which an additive interacts with polymer chains. For example, the smallest set possible contains only two equilibrium constants, $K_{\mathrm{AA}}$ and $K_{\mathrm{AB}}$. The equilibrium constant $K_{\mathrm{AA}}$ describes the growth of a polymer chain with the end unit $\mathbf{A}$ through the addition of $\mathbf{A}$, whereas $K_{\mathrm{AB}}$ relates to the addition of $\mathbf{B}$ (the additive) to the growing $\operatorname{poly}(\mathbf{A})$ chain.

Table 1 lists the possible idealized scenarios in which an additive $\mathbf{B}$ can affect a supramolecular polymerization. If $\mathbf{B}$ is a chain capper, it acts as a perfectly monofunctional monomer preventing further elongation once it is added onto a $\operatorname{poly}(\mathbf{A})$ chain. The values of equilibrium constants

Table 1 Different sets of equilibrium constants that describe the modes of interaction of an additive $\mathbf{B}$ with monomers $\mathbf{A}$ and supramolecular polymers

\begin{tabular}{llllll}
\hline Additive $\mathbf{B}$ & $K_{\mathrm{AA}}$ & $K_{\mathrm{AB}}$ & $K_{\mathrm{BA}}$ & $K_{\mathrm{BB}}$ & Incorporation $\mathbf{A B}$ \\
\hline Chain capper & $\boldsymbol{V}$ & $\boldsymbol{V}$ & $\times$ & $\times$ & Yes \\
Sequestrator & $\boldsymbol{V}$ & $\times$ but $\boldsymbol{K}_{\mathrm{A}_{\mathrm{M}} \mathbf{B}}>0$ & $\times$ but $\boldsymbol{K}_{\mathbf{B A}_{\mathrm{M}}}>0$ & $\times$ & No, only free $\mathbf{A B}$ complexes are present \\
Intercalator & $\boldsymbol{V}$ & $\boldsymbol{V}$ & $\boldsymbol{V}$ & $\times$ & Yes \\
Comonomer & $\boldsymbol{V}$ & $\boldsymbol{V}$ & $\boldsymbol{V}$ & Yes \\
\hline
\end{tabular}

Note: In the case of a sequestrator, the additive forms a complex AB with a monomer which is not incorporated into polymer chains. 
$K_{\mathrm{AA}}$ and $K_{\mathrm{AB}}$ are nonzero and those of $K_{\mathrm{BA}}$ and $K_{\mathrm{BB}}$ are zero, so elongation only occurs for polymer chains with end unit $\mathbf{A}$ (Table 1). With this parameter set, B is only incorporated into polymer chains as a terminal unit (Scheme 1). Another case arises for the sequestrator, when the additive $\mathbf{B}$ complexes the $\mathbf{A}$ monomers to form $\mathbf{A B}$ dimers and $\mathbf{B A B}$ trimers through equilibrium constants $K_{\mathrm{A}_{\mathrm{M}} \mathrm{B}}$ and $K_{\mathrm{BA}_{\mathrm{M}}}$, where $A_{M}$ specifically denotes nonpolymerized monomer $\mathbf{A}$. The sequestering $\mathbf{B}$ effectively reduces the concentration of available $\mathbf{A}$, which can no longer be incorporated into polymer chains (Scheme 1). If an additive $\mathbf{B}$ acts as an intercalator no B-B bonds can be made, but it can insert between two $\mathbf{A}$ monomers in a polymer chain. Association of the intercalator $\mathbf{B}$ to a chain end only prevents further addition of $\mathbf{B}$ monomers, while the growing chain can still be elongated with A monomers (Scheme 1). Accordingly only the value of $K_{\mathrm{BB}}$ is zero, but all other equilibrium constants are nonzero (Table 1 ).

Finally, when additive $\mathbf{B}$ acts as a comonomer, it can both polymerize with other $\mathbf{B}$ monomers as well as with $\mathbf{A}$ monomers. In this case, each of the equilibrium constants is nonzero; elongation can occur for polymers chains with end unit B or A (Table 1 and Scheme 1). Depending on the equilibrium constants and affinities of the monomers for each other, different microstructures can arise from blocky to random or alternating supramolecular copolymers. ${ }^{6}$

In experimental studies, supramolecular polymerizations are typically investigated by changing temperature or concentration. ${ }^{80,81}$ For supramolecular copolymerizations, the molar ratios of the components can be varied as well. Likewise, the effect of an additive on $D P_{\mathrm{n}}$ and $\phi_{\text {agg }}$ can be investigated by changing three parameters, namely, temperature, total concentration, and equivalence of additive $\mathbf{B}$. To demonstrate the expected experimental results, we performed three simulations in which one parameter was varied while the other two were fixed (Figure $5 a-g$ ). To make our calculations more insightful, we have included complementary Matlab scripts in the Supplementary Information (available online only), which allow the reader to perform the simulations with arbitrary thermodynamic parameters.

a)

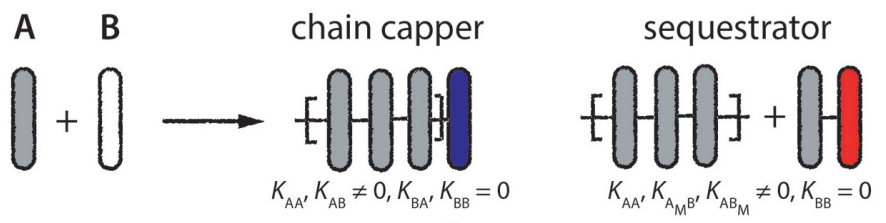

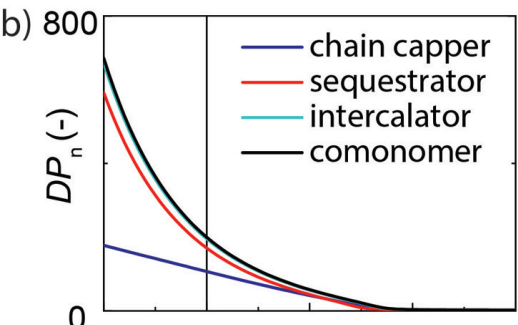

d) 800

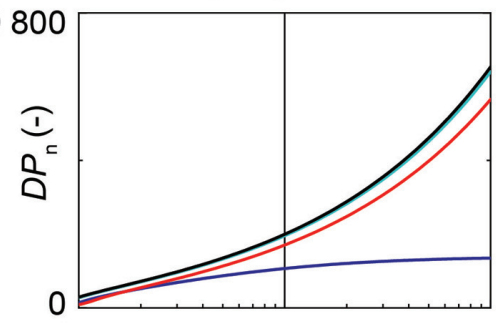

C)

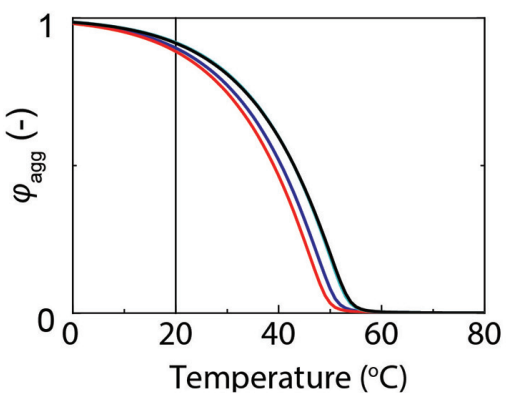

e)

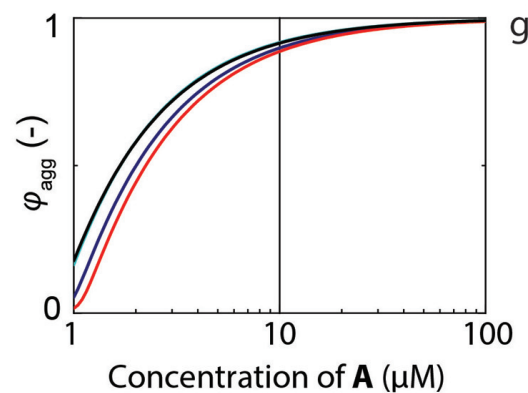

intercalator

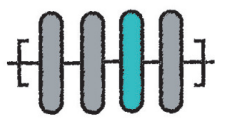

$K_{\mathrm{AA}^{\prime}} K_{\mathrm{AB}^{\prime}} K_{\mathrm{BA}} \neq 0, K_{\mathrm{BB}}=0$

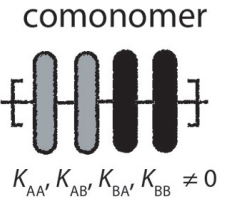

f) 800

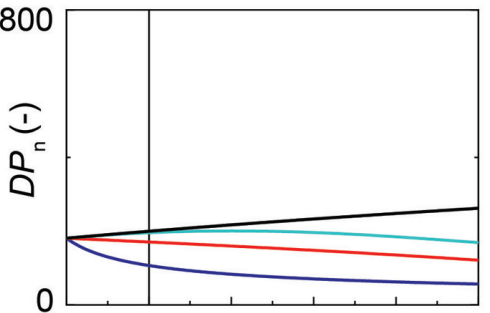

g)

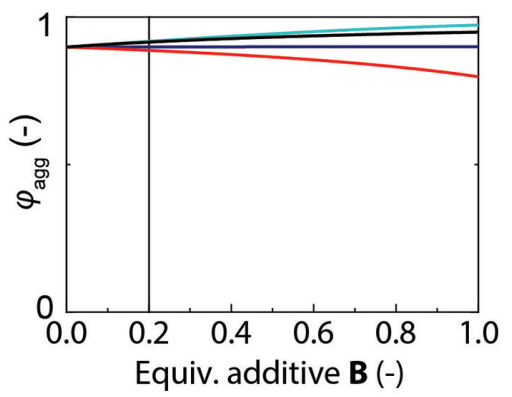

Figure 5 a) Schematic representation of the roles an additive $\mathbf{B}$ can play in the two-component assembly with monomer $\mathbf{A}$. b) Number-average degree of polymerization $\left(D P_{n}\right)$ and $c$ ) degree of aggregation $\left(\phi_{\text {agg }}\right)$ as a function of temperature. General parameters: $c_{A}=1.0 \times 10^{-5} \mathrm{M}, c_{B}=2.0 \times 10^{-6} \mathrm{M}$, $\Delta H_{\mathrm{AA}}=\Delta H_{\mathrm{AB}}=\Delta H_{\mathrm{BA}}=\Delta H_{\mathrm{BB}}=-60.0 \mathrm{kJmol}^{-1}, \Delta S_{\mathrm{AA}}=\Delta S_{\mathrm{AB}}=\Delta S_{\mathrm{BA}}=\Delta S_{\mathrm{BB}}=-90.0 \mathrm{Jmol}^{-1} \mathrm{~K}^{-1}, N P_{\mathrm{A}}=N P_{\mathrm{B}}=20.0 \mathrm{kJmol}{ }^{-1}(\mathrm{see} T \mathrm{Table} 1 \mathrm{for}$ specific cases). d) Number-average degree of polymerization $\left(D P_{n}\right)$ and e) degree of aggregation ( $\left.\phi_{\text {agg }}\right)$ as a function of total concentration. General parameters: $c_{\mathrm{B}} / c_{\mathrm{A}}=0.2, T=293 \mathrm{~K}, K_{\mathrm{AA}}=K_{\mathrm{AB}}=K_{\mathrm{BA}}=K_{\mathrm{BB}}=1.0 \times 10^{6} \mathrm{M}^{-1}, \sigma_{\mathrm{A}}=\sigma_{\mathrm{B}}=2.7 \times 10^{-4}$ (see Table 1 for specific cases). $\mathrm{f}$ ) Number-average degree of polymerization $\left(D P_{n}\right)$ and $g$ ) degree of aggregation $\left(\phi_{\text {agg }}\right)$ for the supramolecular polymerization of monomer $A$ as a function of equivalence of additive B. General parameters of simulation: $c_{\mathrm{A}}=1.0 \times 10^{-5} \mathrm{M}, T=293 \mathrm{~K}, K_{\mathrm{AA}}=K_{\mathrm{AB}}=K_{\mathrm{BA}}=K_{\mathrm{BB}}=1.0 \times 10^{6} \mathrm{M}^{-1}, \sigma_{\mathrm{A}}=\sigma_{\mathrm{B}}=2.7 \times 10^{-4}(\mathrm{see} T \mathrm{Tble} 1$ for sets of equilibrium constants for the types of additive). 
In all cases here, we focus on a moderately cooperative system $\left(\sigma=2.7 \times 10^{-4}\right) .{ }^{82}$ Figure 5 shows changes in $D P_{\mathrm{n}}$ and $\phi_{\text {agg }}$ as a function of the temperature (Figure $5 b, c$ ), overall concentration at a fixed molar ratio of $\mathbf{B}$ (Figure 5d, e), and changes in equivalence of additive B (Figure $5 f, g$ ), respectively.

Supramolecular polymers are highly sensitive to changes in temperature. Decreasing the temperature below the temperature of elongation $\left(T_{\mathrm{e}}\right)$ shifts the equilibrium to a more aggregated state, so both $D P_{\mathrm{n}}$ and $\phi_{\mathrm{agg}}$ increase. The effects on $\phi_{\text {agg }}$ for a chain capper, sequestrator, intercalator, or comonomer when increasing the temperature are small (Figure 5c), albeit that small differences in temperature of elongation $\left(T_{\mathrm{e}}\right)$ can be observed. A significant difference in $D P_{\mathrm{n}}$ with changes in temperature is observed only for $\mathbf{B}$ as a chain capper compared to the other scenarios (Figure 5b). For the modeling, we assumed that there are no changes in the association constants $K$, which determine the composition and likewise length of the two-component assembly of $\mathbf{A}$ and $\mathbf{B}$. In reality, this is rarely the case and chemical equilibria are strongly temperature-dependent. Hence, changes in temperature during experiments to determine the role of additive $\mathbf{B}$ should be avoided.

Changing the total concentration (Figure 5d,e) from 1 to $100 \mu \mathrm{M}$ results in significant changes in both $\phi_{\mathrm{agg}}$ and $D P_{\mathrm{n}}$ for all four types of behavior of additive $\mathbf{B}$. In all cases, $\phi_{\text {agg }}$ decreases at a low concentration, due to inherently decreased stability of supramolecular polymers in this concentration regime. Above $10 \mu \mathrm{M}$, the system is close to fully aggregated and no significant changes in $\phi_{\text {agg }}$ are observed, but substantial effects on $D P_{\mathrm{n}}$ can be observed for the various roles of $\mathbf{B}$. The strongest decrease in $D P_{\mathrm{n}}$ occurs when $\mathbf{B}$ is a chain capper, which prevents further growth of the polymer chains and causes the formation of shorter polymer chains with lower $D P_{\mathrm{n}}$. When $\mathbf{B}$ is a sequestrator, it complexes with A monomers, effectively reducing the concentration of free monomer and thereby reducing $D P_{\mathrm{n}}$. Overall, sequestration is not as effective as chain capping for reducing the chain length and similar degrees of polymerization as for the intercalator and comonomer cases are obtained.

Finally, the effect of increasing the molar ratio of additive $\mathbf{B}$ relative $\mathbf{A}$ shows the most pronounced differences for all scenarios (Figures 5f,g and 6). When $\mathbf{B}$ acts as a chain capper, small amounts of $\mathbf{B}$ added have a strong effect on $D P_{\mathrm{n}}$, while almost no change in $\phi_{\text {agg }}$ is observed. This decrease in $D P_{\mathrm{n}}$ is even more pronounced at higher concentrations. When B acts as a sequestrator, however, a small decrease in $D P_{\mathrm{n}}$ is observed upon the addition of low amounts of $\mathbf{B}$, while larger amounts of $\mathbf{B}$ lead to a stronger decrease in $D P_{\mathrm{n}}$. In contrast to the chain capper, addition of $\mathbf{B}$ as a sequestrator leads to a gradual decrease in $\phi_{\text {agg, }}$, since an increasing amount of $\mathbf{A}$ is sequestered by $\mathbf{B}$ and therefore not aggregated into the polymers. More importantly,
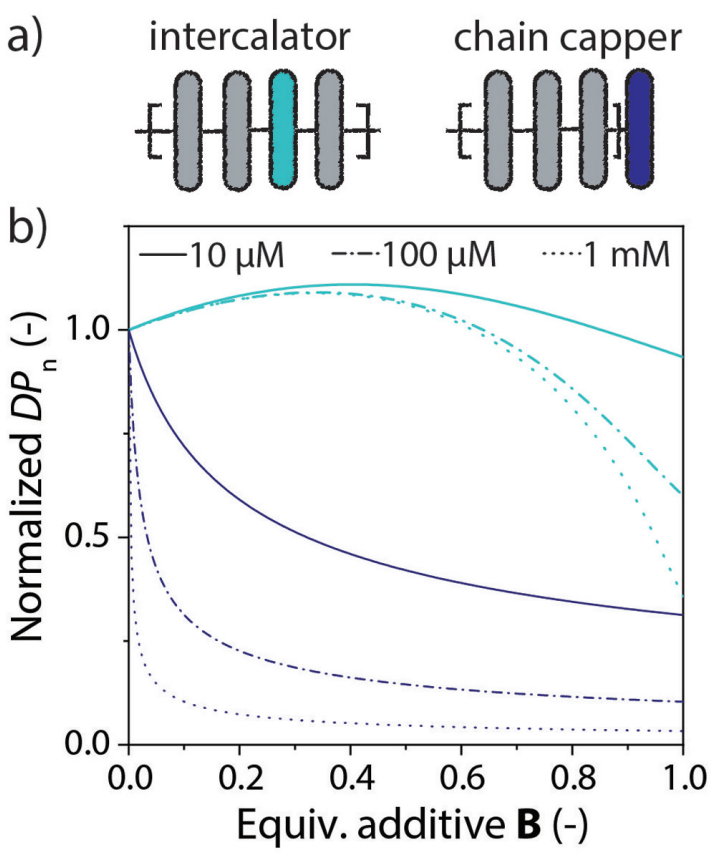

Figure 6 ( $a$ and $b$ ) Changes in chain length of cooperative supramolecular polymers with the addition of a chain capper (blue traces) or an intercalator (cyan traces). Parameters: $c_{\mathrm{A}}=1.0 \times 10^{-5} \mathrm{M}$ (full lines), $1.0 \times 10^{-4} \mathrm{M}$ (dash-dotted lines), and $1.0 \times 10^{-3} \mathrm{M}$ (dotted lines), $T=293 \mathrm{~K}, K_{\mathrm{AA}}=K_{\mathrm{AB}}=K_{\mathrm{BA}}=1.0 \times 10^{6} \mathrm{M}^{-1}, \sigma_{\mathrm{A}}=2.7 \times 10^{-4}$ (see Table 1 for sets of equilibrium constants for the types of additive).

changing the equivalence of $\mathbf{B}$ induces different behaviors for the intercalator and comonomer, which are very difficult to distinguish when changing concentration or temperature. For the case of $\mathbf{B}$ intercalating into poly $(\mathbf{A})$, the polymer length changes in two regimes (Figure 6 ). Upon increasing the $\mathbf{B} / \mathbf{A}$ ratio, $D P_{\mathrm{n}}$ first increases and then decreases. First, at a low ratio of $\mathbf{B}$ content, $D P_{\mathrm{n}}$ increases because more monomers are available to be incorporated into the polymer $\operatorname{poly}(\mathbf{A})$. However, when the concentration of $\mathbf{A B}$ contacts and the concomitant increase in $\mathbf{B}$ chain ends become significant, the polymers cannot be elongated by the addition of $\mathbf{B}$ anymore. As a result, the addition of $\mathbf{B}$ leads to the formation of shorter polymers and the $D P_{\mathrm{n}}$ decreases.

In contrast, when $\mathbf{B}$ acts as a comonomer and $\mathbf{B B}$ contacts are possible, B-terminated polymers can be extended with a consecutive $\mathbf{B}$ monomer and no new polymers need to be formed for $\mathbf{B}$ to aggregate. As a result, when $\mathbf{B}$ acts as a comonomer, $D P_{\mathrm{n}}$ keeps increasing as more $\mathbf{B}$ is added, whereas all other scenarios result in a decrease. Since in both cases $\mathbf{B}$ aggregates with $\mathbf{A}$, a small increase in $\phi_{\text {agg }}$ is observed.

Altogether, it is clear from the plots in Figure 5 that distinguishing between the different roles of $\mathbf{B}$ will require 
to quantify both $D P_{\mathrm{n}}$ and $\phi_{\text {agg. }}$. The addition of chain capper has the most pronounced effect on $D P_{\mathrm{n}}$, especially at low amounts of $\mathbf{B}$ added. $D P_{\mathrm{n}}$ decreases with increasing equivalence of chain capper, whereas $\phi_{\text {agg }}$ does not change. Another signature of a chain capper is a slight increase in $D P_{\mathrm{n}}$ with increasing total concentration and decreasing temperature relative to other types of additives. For $\mathbf{B}$ acting as a sequestrator, a complex $\mathbf{A B}$ with a monomer is formed, which is not incorporated into polymer chains (Scheme 1). Although the same set of equilibrium constants describes sequestration and chain capping, the effects on the degrees of polymerization and aggregation are different (Table 1 ). For a sequestrator, both $D P_{\mathrm{n}}$ and $\phi_{\text {agg }}$ decrease with increasing equivalence of additive. Furthermore, a sequestrator causes a lower $\phi_{\text {agg }}$ as a function of total concentration and temperature in comparison with other types of additives. For an intercalator, both $D P_{\mathrm{n}}$ and $\phi_{\mathrm{agg}}$ increase with increasing equivalence of additive although $\phi_{\text {agg }}$ decreases for high equivalences. In addition, an intercalator causes a higher $D P_{\mathrm{n}}$ and $\phi_{\text {agg }}$ as a function of total concentration and temperature, which is in contrast to a chain capper and a sequestrator. For a comonomer, the effects on $D P_{n}$ and $\phi_{\text {agg }}$ are nearly identical to those of an intercalator. Hence, differentiating between a comonomer and an intercalator in a two-component copolymerization can be experimentally challenging. However, it is easy to differentiate between them individually because only a comonomer interacts with its own type and thereby forms homopolymers.

In summary, the different effects of an additive on the degrees of polymerization and aggregation are rationalized in terms of different sets of equilibrium constants (Table 1), illustrated as different modes of interaction (Scheme 1), and simulated using an equilibrium model of two-component supramolecular copolymerization(Figures 5 and 6). By considering the changes in $D P_{\mathrm{n}}$ and $\phi_{\mathrm{agg}}$, it should be possible to differentiate between a chain capper, a sequestrator, an intercalator, and a comonomer, but experiments need to be conducted as a function of concentration and ratio between $\mathbf{A}$ and $\mathbf{B}$. All in all, to reliably distinguish between the different scenarios on how the additive $\mathbf{B}$ affects the behavior of poly(A), experiments that provide quantitative numbers for both $D P_{\mathrm{n}}$ and $\phi_{\text {agg }}$ in combination with the use of massbalance models need to be performed. Below, we will discuss the experimental techniques available to assess $D P_{\mathrm{n}}$ and $\phi_{\text {agg }}$ in supramolecular copolymerizations.

\section{How to Experimentally Determine the Effect of B on Supramolecular Polymers (poly(A))?}

While the length of covalent polymers can easily be determined by methods such as size exclusion chromatography or viscometry, for supramolecular systems this is inherently more difficult as the systems are dynamic and noncovalent bonds can break and reform. In order to determine the nature of an additive and its influence on the chain length of supramolecular systems under kinetic or thermodynamic control, several analytical techniques have to be combined. ${ }^{83}$ The two parameters to be determined for analyzing the influence of an additive are the numberaveraged degree of aggregation $\phi_{\text {agg }}$ (the number of monomers in an aggregated state) and the degree of polymerization $D P_{\mathrm{n}}=X_{\mathrm{n}}=M_{\mathrm{n}} / M_{0}$ (the number average of monomers in an aggregate). Isodesmic supramolecular systems tend to have high $\phi_{\text {agg }}$ but low $D P_{\mathrm{n}}$, while cooperative systems are usually highly aggregated and show high $D P_{\mathrm{n}}{ }^{80}$

For most of the analytical methods mentioned hereafter, the preparation of the samples and their aging are crucial and it is important to keep the scope and limitations of each of the techniques in mind. Moreover, since the chain length of supramolecular systems changes by simple dilution (see Figure 6), one of the components should be kept constant when preparing mixtures of monomer and additive. By keeping the concentration of $\mathbf{A}$ constant, the changes in chain length only reflect the influence of the additive $\mathbf{B}$ and not the length decrease caused by dilution. Finally, when investigating the role of $\mathbf{B}$ on the chain length of $\operatorname{poly}(\mathbf{A})$ and comparing the different results of various techniques at different concentrations, one has to recognize the concentration dependence in the role of $\mathbf{B}$ (Figures 5 and 6).

Some of the most common techniques used to investigate supramolecular polymerizations are spectroscopic techniques, such as circular dichroism, UV/Vis, and fluorescence spectroscopy. With these techniques, the type of polymerization can be determined (isodesmic or cooperative) by analyzing aggregation-induced changes at an appropriate wavelength over a range of temperatures and/or concentrations. The wavelengths most indicative of aggregation-induced changes can easily be identified by subtracting a spectrum at elevated temperature (molecularly dissolved state) from a spectrum at low temperatures (aggregated state). Spectroscopy is also a powerful tool to derive information about pathway complexity and the different aggregate types formed within a system. Although spectroscopic techniques provide a quick and straightforward method to study supramolecular polymerizations, they can only provide information on the degree of aggregation $\phi_{\text {agg }}$ and not on the degree of polymerization $D P_{\mathrm{n}}$. Thus, spectroscopic investigations alone do not suffice to elucidate the role of an additive in a supramolecular polymerization.

Scattering techniques such as dynamic (DLS) ${ }^{60}$ and static light scattering (SLS $)^{62}$ or small-angle neutron scattering $(\mathrm{SANS})^{59}$ are used to determine the morphology and can give a direct readout of the length of supramolecular 
polymers in solution. The scatter plot of the scattered intensity over the scattering vector $q$ can be fitted with appropriate models corresponding to the geometry of the aggregate to get an estimate of the chain length. ${ }^{62}$ With DLS, information about the hydrodynamic correlation length and relaxation modes in the sample can be derived, which can be compared to rheology data. For both techniques, it is important to know the overlap concentration $c^{*}$ of the respective systems between independent aggregates and polymer networks. Above this concentration, only the distance between the entanglements is measured and not the chain length of an individual fiber. ${ }^{62}$

Another class of analytical techniques is microscopybased techniques such as (cryo)-TEM, AFM, and superresolution microscopy. Depending on the solvent and the conditions of sample preparation, snapshots of the 1D and 2D morphologies and length of supramolecular systems can be obtained. For multicomponent systems, these techniques offer exciting possibilities to follow the assembly of block copolymers by selectively color coding and labeling the individual components. ${ }^{19,35}$ Although microscopic techniques are very powerful, they are not suitable for quantitative assumptions about the length of aggregates as only statistically nonsignificant numbers of polymer fibers can be investigated within a reasonable time. Moreover, the influences of sample preparation, drying effects, ${ }^{84}$ and interaction with the substrate also have to be considered when analyzing data derived from microscopy techniques.

At high concentrations, the chain length and the number of entanglements increase, and thereby the viscosity of the polymer solution. This can be studied using rheology, which provides information about degree of polymerization of the supramolecular system, and the mechanisms and timescales of relaxation. ${ }^{7,60,63,65}$ The incorporation of an additive, such as a chain capper or a sequestrator, decreases the polymer length and thereby the viscosity of the solution. Similarly, vapor pressure osmometry has successfully been employed to determine $D P_{\mathrm{n}}$ of supramolecular capped polymers. $^{52}$

To determine the presence of smaller aggregates such as dimers, trimers, or tetramers formed by sequestrators, solution diffusion ordered spectroscopy (DOSY) NMR techniques are feasible. ${ }^{75,85}$ Different compounds or aggregates in a mixture are spectroscopically resolved depending on their diffusion coefficient $D$, size, and shape. Although the direct determination of length is often difficult with this technique, it can give many insights into the distribution of species formed in the presence of an additive.

A summary of the analytical techniques and the parameters they determine $\left(D P_{\mathrm{n}}\right.$ or $\left.\phi_{\mathrm{agg}}\right)$ is given in Table 2. We would like to stress that in most practical situations, the $\mathbf{B}$ additive can also exhibit a combination of the four roles outlined in this review. As a result, it is of
Table 2 Summary of analytical techniques and which parameters can be experimentally determined

\begin{tabular}{llll}
\hline Techniques & $D P_{\mathrm{n}}$ & $\phi_{\text {agg }}$ & Parameters \\
\hline CD, UV/Vis, fluorescence & No & Yes & Pathways, mechanism \\
$\begin{array}{l}\text { Scattering } \\
\text { (SLS/DLS, SANS/SAXS) }\end{array}$ & Yes & No & Length, morphology \\
AFM, (cryo)TEM, SRM & Yes & No & Length, morphology \\
Rheology, osmometry & Yes & No & Relaxation modes \\
DOSY NMR & No & No & Diffusion coefficient \\
\hline
\end{tabular}

critical importance to acquire data of high quality, since small experimental differences and details can point to profoundly different molecular mechanisms of chain-length control.

And last but not least, the sample preparation is critical in the control of the chain length of these supramolecular systems. Devices such as a vortex mixer and a sonication bath are commonly used in the laboratory but their impacts on the resulting architectures are rarely described. ${ }^{25,86,87}$ In the case of kinetically controlled supramolecular polymerizations in particular, the sample preparation and history critically influences the supramolecular polymers observed. A rigorous description of the protocols used to prepare the samples seems essential to ensure a full comprehension of the systems studied.

\section{Conclusions and Outlook}

In this review, we provide guidelines to elucidate the role of additives in supramolecular polymerization, and in particular how they influence the length of cooperative supramolecular (co)polymers. This study makes clear that a combined experimental and theoretical approach is essential to determine the mode of action of an additive $\mathbf{B}$ to a supramolecular polymer made of monomers A. These additives are classified as a chain capper, a sequestrator, an intercalator, or a comonomer. The results obtained have highlighted the intrinsic complexity and sensitivity of these multicomponent systems, where many parameters come into play such as temperature, concentration, and molar ratios of components. In particular, the concentration of both components is an essential variable to consider as the composition of the supramolecular copolymers changes at different concentration regimes. Moreover, guidelines on the analytical methods available to characterize these mixtures have been provided. Techniques that are able to not only characterize supramolecular multicomponent systems at different length scales, but also at different time scales and preferably both at the same time, are crucial. Super-resolution microscopy techniques are being developed and push down the reachable limits of molecular resolution. More progress in 
this direction will lead to a deeper comprehension and control over supramolecular systems.

Supramolecular polymers hold great promises for the development of life-like molecular systems and materials with unprecedented functions. The challenge is to reach the same level of precision in the synthesis of supramolecular polymers as is currently possible in sequence-defined covalent polymerization techniques. ${ }^{88}$ The first steps have proven that chain lengths in supramolecular polymers can be tuned both for isodesmic and cooperative supramolecular polymerizations. Next steps to translate changes in monomer sequence into macroscopic effects have also been taken. ${ }^{7}$ The present work adds to the comprehensive understanding of the mechanisms of multicomponent supramolecular polymerizations to control the molecular structures of (co)polymers. We propose that such a generalized approach combining experimental studies with theoretical modeling will serve as a guideline to design and construct complex functional supramolecular polymers.

\section{Funding Information}

The authors received funding from the Netherlands Organization for Scientific Research (NWO-TOP PUNT grant No. 10018944, NWO-Veni grant 722.017.003, and ECHO grant 713.016.003), the European Union's Horizon 2020 Research and Innovation program (Marie Sklodowska-Curie grant agreement No. 642083), and the Dutch Ministry of Education, Culture, and Science (Gravity program 024.001.035).

\section{Acknowledgments}

The authors would like to thank Albert J. Markvoort and Huub M. M. ten Eikelder for providing the mathematical models for the two-component polymerization.

\section{Supporting Information}

Supporting information for this article is available online at https://doi.org/10.1055/s-0040-1708813.

\section{References}

(1) Staudinger, H. Ber. Dtsch. Chem. Ges. 1920, 53, 1073.

(2) De Greef, T. F. A.; Smulders, M. M. J.; Wolffs, M.; Schenning, A. P. H. J.; Sijbesma, R. P.; Meijer, E. W. Chem. Rev. 2009, 109, 5687.

(3) Matern, J.; Dorca, Y.; Sánchez, L.; Fernández, G. Angew. Chem. Int. Ed. 2019, 58, 16730.

(4) Wehner, M.; Würthner, F. Nat. Rev. Chem. 2020, 4, 38.

(5) Besenius, P. J. Polym. Sci., Part A: Polym. Chem. 2017, 55, 34.
(6) Adelizzi, B.; Van Zee, N. J.; de Windt, L. N. J.; Palmans, A. R. A.; Meijer, E. W. J. Am. Chem. Soc. 2019, 141, 6110.

(7) Sijbesma, R. P.; Beijer, F. H.; Brunsveld, L.; Folmer, B. J. B.; Hirschberg, J. H. K. K.; Lange, R. F. M.; Lowe, J. K. L.; Meijer, E. W. Science 1997, 278, 1601.

(8) Berl, V.; Schmutz, M.; Krische, M. J.; Khoury, R. G.; Lehn, J-M. Chem. Eur. J. 2002, 8, 1227.

(9) Harada, A.; Takashima, Y.; Yamaguchi, H. Chem. Soc. Rev. 2009, 38, 875.

(10) Yang, L.; Tan, X.; Wang, Z.; Zhang, X. Chem. Rev. 2015, 115, 7196.

(11) Michelsen, U.; Hunter, C. A. Angew. Chem. Int. Ed. 2000, 39, 764.

(12) Beldjoudi, Y.; Narayanan, A.; Roy, I.; Pearson, T. J.; Cetin, M. M.; Nguyen, M. T.; Krzyaniak, M. D.; Alsubaie, F. M.; Wasielewski, M. R.; Stupp, S. I.; Stoddart, J. F. J. Am. Chem. Soc. 2019, 141, 17783.

(13) Zhao, D.; Moore, J. S. Org. Biomol. Chem. 2003, 1, 3471.

(14) Wang, X.; Guerin, G.; Wang, H.; Wang, Y.; Manners, I.; Winnik, M. A. Science 2007, 317, 644.

(15) Gilroy, J. B.; Gädt, T.; Whittell, G. R.; Chabanne, L.; Mitchels, J. M.; Richardson, R. M.; Winnik, M. A.; Manners, I. Nat. Chem. 2010, 2, 566.

(16) Patra, S. K.; Ahmed, R.; Whittell, G. R.; Lunn, D. J.; Dunphy, E. L.; Winnik, M. A.; Manners, I. J. Am. Chem. Soc. 2011, 133, 8842.

(17) Qiu, H.; Hudson, Z. M.; Winnik, M. A.; Manners, I. Science 2015, $347,1329$.

(18) Rupar, P. A.; Chabanne, L.; Winnik, M. A.; Manners, I. Science 2012, 337, 559 .

(19) Hudson, Z. M.; Lunn, D. J.; Winnik, M. A.; Manners, I. Nat. Commun. 2014, 5, 3372.

(20) Pearce, S.; He, X.; Hsiao, M-S.; Harniman, R. L.; MacFarlane, L. R.; Manners, I. Macromolecules 2019, 52, 6068.

(21) Petzetakis, N.; Dove, A. P.; O'Reilly, R. K. Chem. Sci. 2011, 2, 955.

(22) Robinson, M. E.; Lunn, D. J.; Nazemi, A.; Whittell, G. R.; De Cola, L.; Manners, I. Chem. Commun. 2015, 51, 15921.

(23) Robinson, M. E.; Nazemi, A.; Lunn, D. J.; Hayward, D. W.; Boott, C. E.; Hsiao, M. S.; Harniman, R. L.; Davis, S. A.; Whittell, G. R.; Richardson, R. M.; De Cola, L.; Manners, I. ACS Nano 2017, 11, 9162.

(24) Guérin, G.; Wang, H.; Manners, I.; Winnik, M. A.J. Am. Chem. Soc. 2008, 130, 14763.

(25) Carnall, J. M. A.; Waudby, C. A.; Belenguer, A. M.; Stuart, M. C. A.; Peyralans, J. J-P.; Otto, S. Science 2010, 327, 1502.

(26) Pal, A.; Malakoutikhah, M.; Leonetti, G.; Tezcan, M.; ColombDelsuc, M.; Nguyen, V. D.; van der Gucht, J.; Otto, S. Angew. Chem. Int. Ed. 2015, 54, 7852.

(27) Colomb-Delsuc, M.; Mattia, E.; Sadownik, J. W.; Otto, S. Nat. Commun. 2015, 6, 7427.

(28) Ogi, S.; Sugiyasu, K.; Manna, S.; Samitsu, S.; Takeuchi, M. Nat. Chem. 2014, 6, 188.

(29) Ogi, S.; Grzeszkiewicz, C.; Würthner, F. Chem. Sci. 2018, 9, 2768.

(30) Ogi, S.; Stepanenko, V.; Sugiyasu, K.; Takeuchi, M.; Würthner, F.J. Am. Chem. Soc. 2015, 137, 3300.

(31) Ma, X.; Zhang, Y.; Zhang, Y.; Liu, Y.; Che, Y.; Zhao, J. Angew. Chem. Int. Ed. 2016, 55, 9539.

(32) Wagner, W.; Wehner, M.; Stepanenko, V.; Ogi, S.; Würthner, F. Angew. Chem. Int. Ed. 2017, 56, 16008.

(33) Jarrett-Wilkins, C.; He, X.; Symons, H. E.; Harniman, R. L.; Faul, C. F. J.; Manners, I. Chem. Eur. J. 2018, 24, 15556.

(34) Hu, K.; Liu, Y.; Xiong, W.; Gong, Y.; Che, Y.; Zhao, J. Chem. Mater. 2019, 31, 1403. 
(35) Wagner, W.; Wehner, M.; Stepanenko, V.; Würthner, F. J. Am. Chem. Soc. 2019, 141, 12044.

(36) Ogi, S.; Matsumoto, K.; Yamaguchi, S. Angew. Chem. Int. Ed. 2018, 57, 2339.

(37) Ghosh, G.; Ghosh, S. Chem. Commun. 2018, 54, 5720.

(38) Haedler, A. T.; Meskers, S. C. J.; Zha, R. H.; Kivala, M.; Schmidt, HW.; Meijer, E. W. J. Am. Chem. Soc. 2016, 138, 10539.

(39) Singh, A.; Joseph, J. P.; Gupta, D.; Sarkar, I.; Pal, A. Chem. Commun. 2018, 54, 10730.

(40) Liu, Y.; Peng, C.; Xiong, W.; Zhang, Y.; Gong, Y.; Che, Y.; Zhao, J. Angew. Chem. Int. Ed. 2017, 56, 11380.

(41) Huang, Z.; Qin, B.; Chen, L.; Xu, J-F.; Faul, C. F. J.; Zhang, X. Macromol. Rapid Commun. 2017, 38, 1700312.

(42) Kang, J.; Miyajima, D.; Mori, T.; Inoue, Y.; Itoh, Y.; Aida, T. Science 2015, 347, 646.

(43) Endo, M.; Fukui, T.; Jung, S. H.; Yagai, S.; Takeuchi, M.; Sugiyasu, K. J. Am. Chem. Soc. 2016, 138, 14347.

(44) Jung, S. H.; Bochicchio, D.; Pavan, G. M.; Takeuchi, M.; Sugiyasu, K. J. Am. Chem. Soc. 2018, 140, 10570.

(45) Pal, D. S.; Kar, H.; Ghosh, S. Chem. Commun. 2018, 54(08): 928.

(46) Fukui, T.; Sasaki, N.; Takeuchi, M.; Sugiyasu, K. Chem. Sci. 2019, $10,6770$.

(47) Dhiman, S.; George, S. J. Bull. Chem. Soc. Jpn. 2018, 91, 687.

(48) Sorrenti, A.; Leira-Iglesias, J.; Markvoort, A. J.; de Greef, T. F. A.; Hermans, T. M. Chem. Soc. Rev. 2017, 46, 5476.

(49) van Esch, J. H.; Klajn, R.; Otto, S. Chem. Soc. Rev. 2017, 46, 5474.

(50) Walther, A. Adv. Mater. 2019, 1905111. Doi: 10.1002/ adma.201905111 [epub ahead of print].

(51) Jain, A.; Dhiman, S.; Dhayani, A.; Vemula, P. K.; George, S. J. Nat. Commun. 2019, 10, 450.

(52) Boekhoven, J.; Hendriksen, W. E.; Koper, G. J. M.; Eelkema, R.; van Esch, J. H. Science 2015, 349, 1075.

(53) Leira-Iglesias, J.; Tassoni, A.; Adachi, T.; Stich, M.; Hermans, T. M. Nat. Nanotechnol. 2018, 13, 1021.

(54) Rieß, B.; Grötsch, R. K.; Boekhoven, J. Chem 2020, 6, 1-27.

(55) Markvoort, A. J.; Ten Eikelder, H. M. M.; Hilbers, P. A. J.; De Greef, T. F. A.; Meijer, E. W. Nat. Commun. 2011, 2, 1.

(56) ten Eikelder, H. M. M.; Markvoort, A. J.; de Greef, T. F. A.; Hilbers, P. A. J. J. Phys. Chem. B 2012, 116, 5291.

(57) Korevaar, P. A.; Schaefer, C.; de Greef, T. F. A.; Meijer, E. W. J. Am. Chem. Soc. 2012, 134, 13482.

(58) Boileau, S.; Bouteiller, L.; Lauprêtre, F.; Lortie, F. New J. Chem. 2000, 24, 845 .

(59) Pinault, T.; Andrioletti, B.; Bouteiller, L. Beilstein J. Org. Chem. 2010, 6, 869.

(60) Knoben, W.; Besseling, N. A. M.; Bouteiller, L.; Stuart, C. M. Phys. Chem. Chem. Phys. 2005, 7, 2390.

(61) Lortie, F.; Boileau, S.; Bouteiller, L.; Chassenieux, C.; Lauprêtre, F. Macromolecules 2005, 38, 5283.

(62) Knoben, W.; Besseling, N. A. M.; Cohen Stuart, M. A. Macromolecules 2006, 39, 2643.

(63) Knoben, W.; Besseling, N. A. M.; Cohen Stuart, M. A. J. Chem. Phys. 2007, 126, 024907.
(64) Knoben, W.; Besseling, N. A. M.; Stuart, M. A. Langmuir 2007, 23 , 6095.

(65) Pinault, T.; Cannizzo, C.; Andrioletti, B.; Ducouret, G.; Lequeux, F.; Bouteiller, L. Langmuir 2009, 25, 8404.

(66) Pal, D. S.; Kar, H.; Ghosh, S. Chem. Eur. J. 2016, 22, 16872.

(67) Smulders, M. M. J.; Nieuwenhuizen, M. M. L.; Grossman, M.; Filot, I. A. W.; Lee, C. C.; de Greef, T. F. A.; Schenning, A. P. H. J.; Palmans, A. R. A.; Meijer, E. W. Macromolecules 2011, 44, 6581.

(68) Long, A.; Jean, M.; Albalat, M.; Vanthuyne, N.; Giorgi, M.; Górecki, M.; Dutasta, J.; Martinez, A. Chirality 2019, 31, 910.

(69) Karunakaran, S. C.; Cafferty, B. J.; Peláez-Fernández, M.; Neselu, K.; Schmidt-Krey, I.; Fernandez-Nieves, A.; Schuster, G. B.; Hud, N. V. Polym. Chem. 2018, 9, 5268.

(70) Karunakaran, S. C.; Cafferty, B. J.; Jain, K. S.; Schuster, G. B.; Hud, N. V. ACS Omega 2019, 5, 344.

(71) Weyandt, E.; ter Huurne, G. M.; Vantomme, G.; Markvoort, A. J.; Palmans, A. R. A.; Meijer, E. W. J. Am. Chem. Soc 2020, 142, 6295

(72) Ahrens, M. J.; Kelley, R. F.; Dance, Z. E. X.; Wasielewski, M. R. Phys. Chem. Chem. Phys. 2007, 9, 1469.

(73) Helmich, F.; Lee, C. C.; Nieuwenhuizen, M. M. L.; Gielen, J. C.; Christianen, P. C. M.; Larsen, A.; Fytas, G.; Leclère, P. E. L. G.; Schenning, A. P. H. J.; Meijer, E. W. Angew. Chem. Int. Ed. 2010, 49, 3939.

(74) Hirose, T.; Helmich, F.; Meijer, E. W. Angew. Chem. Int. Ed. 2013, $52,304$.

(75) Vantomme, G.; Ter Huurne, G. M.; Kulkarni, C.; ten Eikelder, H. M. M.; Markvoort, A. J.; Palmans, A. R. A.; Meijer, E. W. J. Am. Chem. Soc. 2019, 141, 18278.

(76) Kumar, J.; Tsumatori, H.; Yuasa, J.; Kawai, T.; Nakashima, T. Angew. Chem. Int. Ed. 2015, 54, 5943.

(77) Martin, R. B. Chem. Rev. 1996, 96, 3043.

(78) Goldstein, R. F.; Stryer, L. Biophys. J. 1986, 50, 583.

(79) Ten Eikelder, H. M. M.; Markvoort, A. J. Acc. Chem. Res. 2019, 52, 3465.

(80) Smulders, M. M. J.; Nieuwenhuizen, M. M. L.; de Greef, T. F. A.; van der Schoot, P.; Schenning, A. P. H. J.; Meijer, E. W. Chem. Eur. J. 2010, 16, 362.

(81) Fernández, G.; Stolte, M.; Stepanenko, V.; Würthner, F. Chem. Eur. J. 2013, 19, 206.

(82) Kulkarni, C.; Meijer, E. W.; Palmans, A. R. A. Acc. Chem. Res. 2017, 50, 1928.

(83) Vill, R.; Gülcher, J.; Khalatur, P.; Wintergerst, P.; Stoll, A.; Mourran, A.; Ziener, U. Nanoscale 2019, 11, 663.

(84) Mears, L. L. E.; Draper, E. R.; Castilla, A. M.; Su, H., Zhuola, Dietrich, B.; Nolan, M. C.; Smith, G. N.; Doutch, J.; Rogers, S.; Akhtar, R.; Cui, H.; Adams, D. J. Biomacromolecules 2017, 18, 3531.

(85) Sanguramath, R. A.; Nealey, P. F.; Shenhar, R. Chem. Eur. J. 2016, $22,10203$.

(86) Steinlein, C.; Kreger, K.; Schmidt, H. Macromol. Mater. Eng. 2019, 304, 1900258.

(87) Ribó, J. M.; Crusats, J.; Sagués, F.; Claret, J.; Rubires, R. Science 2001, 292, 2063.

(88) Lutz, J-FJF.; Ouchi, M.; Liu, D. R.; Sawamoto, M. Science 2013, 341, 1238149 . 